\title{
EFFICACY OF A MULTIMODAL PHYSIOTHERAPY TREATMENT PROGRAM FOR POSTURAL DISORDERS AND PAIN: A CASE REPORT
}

\author{
Kirkke Reisberg ${ }^{1,2}$, Caris-Helena KauP ${ }^{1}$ \\ ${ }^{1}$ Department of Physiotherapy, Tartu Health Care College, Tartu, Estonia \\ ${ }^{2}$ Institute of Sport Sciences and Physiotherapy, University of Tartu, Tartu, Estonia
}

\begin{abstract}
The participant of this study was a 40-year-old female, who mainly complained of middle thoracic stiffness and pain in extension at the mid thoracic level with hyperkyphosis, forward head and mild thoracic dextroscoliosis. The subject participated in multimodal home-based physiotherapy program with the duration of 9 months, consisting of posture exercises, soft tissue massage therapy and thoracic manipulations. Comparison of initial and final evaluation revealed the improvement in all evaluated variables, including the reduction of thoracic hyperkyphosis, forward head posture and thoracic dextroscoliosis, freer and less painful thoracic spine extension mobility, no pain in the sacroiliac joint, and increased satisfaction with the posture. There was also notable improvement in the algometry of the paraspinal muscles, equalization of functional lower-leg length and rib-pelvic distance of both sides of body. In conclusion, the proposed physiotherapy protocol can be beneficial in addressing postural faults such as thoracic hyperkyphosis, forward head and scoliosis. However, further research is needed with a larger sample.
\end{abstract}

Keywords: hyperkyphosis, forward head posture, scoliosis, physiotherapy

\section{INTRODUCTION}

The normal kyphotic curvature of the thoracic spine regarding Cobb angle measurement falls between $20^{\circ}$ and $40^{\circ}$. Larger kyphosis angle is viewed as hyperkyphosis [15]. Lateral curvature of the spine $>10^{\circ}$ in the coronal plane, with rotation of the vertebrae (pedicles or spinous processes toward the concavity of the curvature) within the curve is regarded as scoliosis [26, 37]. 
Only a few studies have evaluated the associations between spinal deformations and pain. Many studies have found hyperkyphosis to be associated with upper back pain $[13,32,35]$, but some found that hyperkyphosis did not cause substantial chronic back pain in older women [14]. Idiopathic scoliosis scarcely causes pain [37], yet it may sometimes induce posterior chest wall pain on the region of the rib hump [21]. In a case report a 76-yearold woman with excessive thoracic kyphosis and lumbar scoliosis reported to have low back pain [7]. Meanwhile it should be kept in mind that the lifetime prevalence of nonspecific back pain is $70 \%$ in the normal population and should not be attributed to scoliosis [37]. Still, curvature $>45^{\circ}$ in adolescence predicted significantly greater back pain intensity further in adulthood [19]. Additionally, to pain, spinal deformations might lead to dissatisfaction with the bodily appearance [7, 29].

No matter that physiotherapy (PT) and braces are often used to reverse thoracic hyperkyphosis and scoliosis, and to reduce discomfort or pain, there is limited and controversial experimental evidence about their effectiveness in adulthood [5, 8]. Yet, some studies suggest that conservative treatment should be considered first [8], and surgical treatment is recommended in adults with progression of kyphosis, refractory pain and loss of balance [8], while the others state that PT and braces have a relatively minor role in adult scoliosis and surgery may be the best treatment option in symptomatic scoliosis with severe deformity [37]. Thus, there is no clear opinion about the most suitable treatment protocol and the efficacy of exercises and other PT methods in case of hyperkyphosis of thoracic spine and scoliosis.

Forward head posture is defined as the forward displacement of the head from the gravity line, where increased extension of the upper cervical spine (hyperlordosis) and increased flexion of the lower cervical spine (hypolordosis) and upper thoracic spine has occurred [12, 17]. There is evidence, that thoracic hyperkyphosis and forward head posture are associated, but it is still not clear, which one is the cause and consequence [34]. It is also suggested that the dysfunction of lower cervical spine can induce upper thoracic back pain [12]. Additionally, there is data from one study that more than half of patients with neck pain had forward head posture [11], yet another study showed that forward head posture was not related to neck pain or disability [17]. In order to restore normal alignment of neck and reduce chronic neck pain, the activation of neck flexors through craniocervial flexion exercise, cervical flexion exercise and their combination, has been applied in studies $[10,23]$. 
The purpose of this study was to investigate the effect of multimodal PT program on spinal disorders, such as forward head posture, hyperkyphosis and scoliosis, and on back pain/stiffness.

\section{MATERALS AND METHODS}

The study subject was a 40 -year-old female, $170 \mathrm{~cm}$ in height and $68 \mathrm{~kg}$ in weight, who complained of thoracic hyperkyphosis, forward head posture and thoracic dextroscoliosis. She also reported to suffer from thoracic stiffness (right $>$ left) and nonradiating pain with extension at the T4-7 level for years. In the last two years mild pain in right-sided sacroiliac joint (SI) region had also emerged.

The subject reported her pains were rated as $3 / 10$ for her mid back in extension ( $0=$ no pain; $10=$ worst pain ever), $1-2 / 10$ for SI joint.

The subject was diagnosed mild thoracic dextroscoliosis by occupational physician in 2015. She had not undergone spinal imaging and treatment, including medical treatment, for her condition.

Visual observation alongside with photographic recordings were used for postural assessment [33]. Skin marking over the spinous processes was used to detect any spinal misalignments in the frontal plane.

An algometer (Wagner Instruments FPK 20, Greenwich, USA) was used to measure the pressure pain threshold of paraspinal muscles bilaterally from superior nuchal line down to posterior superior iliac spine, applying pressure after every $5 \mathrm{~cm}$ (Figure 1, A). The subject was instructed to give a signal immediately when the sensation of pressure became a painful sensation in order to establish her pain threshold $\left(\mathrm{kg} / \mathrm{cm}^{2}\right)$ [3]. The values of individual points of each side of body were summed and divided with the number of points.
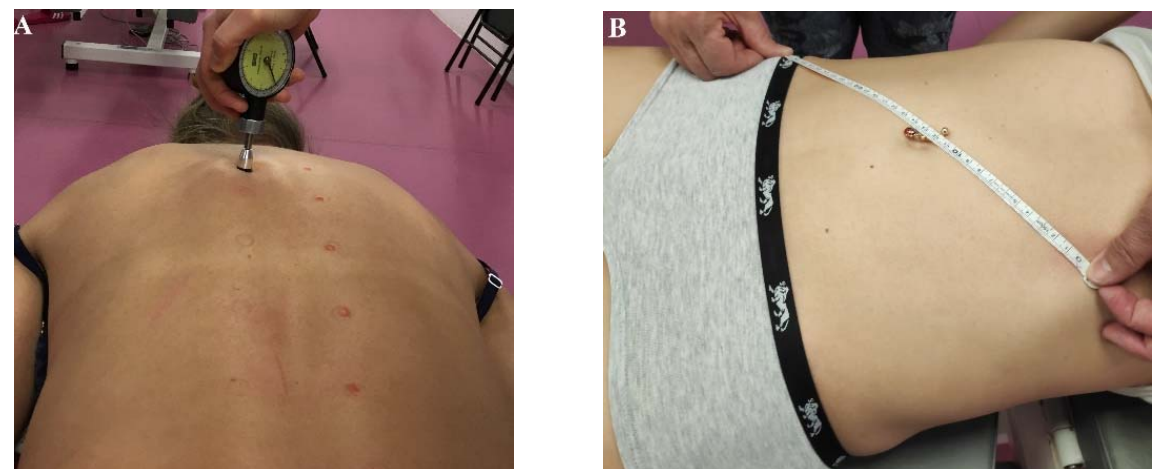

Figure 1. A. Using algometer to measure pain pressure threshold of paraspinal muscles. B. Measurement of rib-pelvic distance. 
The rib-pelvis distance was defined as the distance between the costal margin on the level of 9-10th rib and opposite anterior superior iliac spine (ASIS) and was measured by means of a tape measure.

To identify whether the subject had lower-limb length discrepancies, first the distance between upper margin of greater trochanter and lower margin of lateral malleolus was measured [28] (Figure 2, A), and thereafter we measured the distance between ASIS and lower margin of lateral malleolus by measuring tape (Figure 2, B) [9, 36, 24].

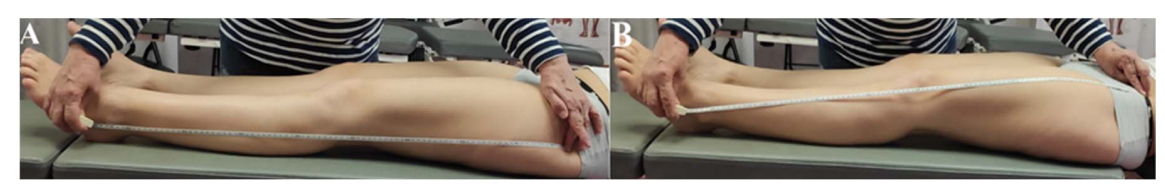

Figure 2. Measurement of structural (A) and functional (B) lower-limb length.

Home-based multimodal PT program lasted 9 months, from December 2018 to September 2020. It consisted of rolling with massage roller (Figure 3, C), end-range exercises to reduce cervical and thoracic spine mobility limitations (Figure 3, K), spinal extensor (Figure 3, A, B) and deep neck flexor muscle strengthening exercises (Figure 3, D), scapulothoracic exercises for serratus anterior (Figure 3, F, G) and lower trapezius (Figure 3, E) muscle strengthening, as well incorporating self-correction exercises in order to counteract scoliotic deformation (Figure 3, H, I, J), stretching exercises for pectoralis major and quadratus lumborum muscles (Figure 3, L), and also hip extensor strengthening exercises $[1,2,4,6,8,20,22,30,31]$ (Table 1), and integrating the corrected posture into daily activities [22,39]. During the first week exercises were performed 3-4 times a week and in the following 2-5 weeks were progressed to 6 times a week, thereafter step-by-step in a decreasing manner 5 times a week in 6-10 weeks, 3 times a week in 11-22 weeks and finally 2 times a week in $23-40$ weeks. The subject was treated also with 10 minutes soft tissue back massage [6] once a week and monthly with thoracic thrust manipulations $[16,25,27,38]$. The subject consented to the publication of this report, including pictures. 
Table 1. List of exercises performed during physiotherapy program.

\begin{tabular}{l}
\hline Standing thoracic extensions \\
\hline Thoracic extension mobilization on the wall \\
\hline Cat/camel \\
\hline Neck and thoracic spine mobilizations with massage roller \\
\hline Thoracic spine rotations to left with TheraBand \\
\hline Kneeling thoracic spine rotations \\
\hline Thoracic lateral translations to left with TheraBand \\
\hline TheraBand diagonal shoulder flexion \\
\hline Pushing against wall \\
\hline Kneeling scapular protraction \\
\hline Thumb up (lower trapezius) \\
\hline Pectoralis major stretch \\
\hline Quadratus lumborum stretch \\
\hline Chin tucks (supine and standing) \\
\hline Bridge \\
\hline Half squats
\end{tabular}

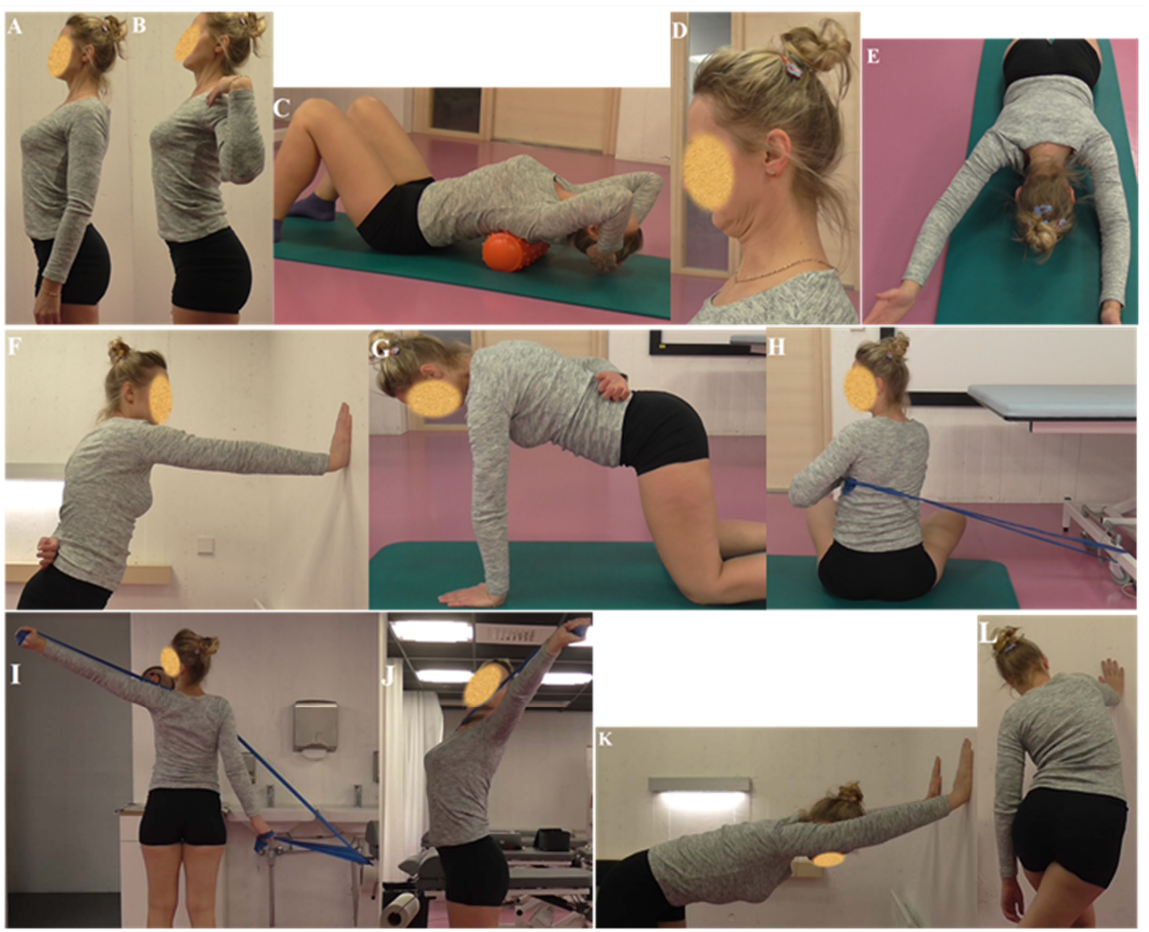

Figure 3. Illustrated examples of exercises applied during study. A: Thoracic spine extension. B: Thoracic spine extension, hands on shoulders. C: Thoracic spine mobilization with massage roller. D: Chin tuck for activation of the deep neck flexors. E: Activation of lower trapezius. F, G: Activation of serratus anterior. H: Trunk rotation with TheraBand. I, J: TheraBand diagonal shoulder flexion. K: Thoracic extension mobilization on the wall. L: Quadratus lumborum stretch. 


\section{RESULTS}

Initially the subject complained of mid thoracic stiffness and pain $(3 / 10)$ in extension at the T4-7 level, forward head posture, thoracic hyperkyphosis and dextroscoliosis, as well of right sacroiliac joint pain $(1-2 / 10)$. After multimodal PT program the thoracic spine extension mobility was remarkably freer and less painful (1/10). Pain around the sacroiliac joint had resolved $(0 / 10)$. The subject felt considerably more comfortable with her neck and thoracic spine posture and reported the incorporation of improved posture habits into her daily routine.

Initial posture analysis revealed several postural faults, the subject had forward head posture, thoracic hyperkyphosis and increased lumbar lordosis, her head was also slightly tilted to left and turned to right, additionally some slight postural asymmetries between right and left side, such as raised left scapula, increased left arm-thoracic space, raised left gluteal and knee joint line were detected. Mild thoracic dextroscoliosis, and correspondingly a rib hump on right during the Adam's forward bending test was is identified. Compared to baseline, the improvements in all aspects of aforementioned postural deviations were detected after the PT program, the most notable was the reduction of thoracic hyperkyphosis.

The initial pressure pain threshold was on right and left body side $5.6 \mathrm{~kg} / \mathrm{cm}^{2}$ and $6 \mathrm{~kg} / \mathrm{cm}^{2}$, respectively. At the end of a study the pressure pain threshold was $8 \mathrm{~kg} / \mathrm{cm}^{2}$ (increased by $2.4 \mathrm{~kg} / \mathrm{cm}^{2}$ ) and $7.9 \mathrm{~kg} / \mathrm{cm}^{2}$ (increased $1.9 \mathrm{~kg} \mathrm{~kg} / \mathrm{cm}^{2}$ ).

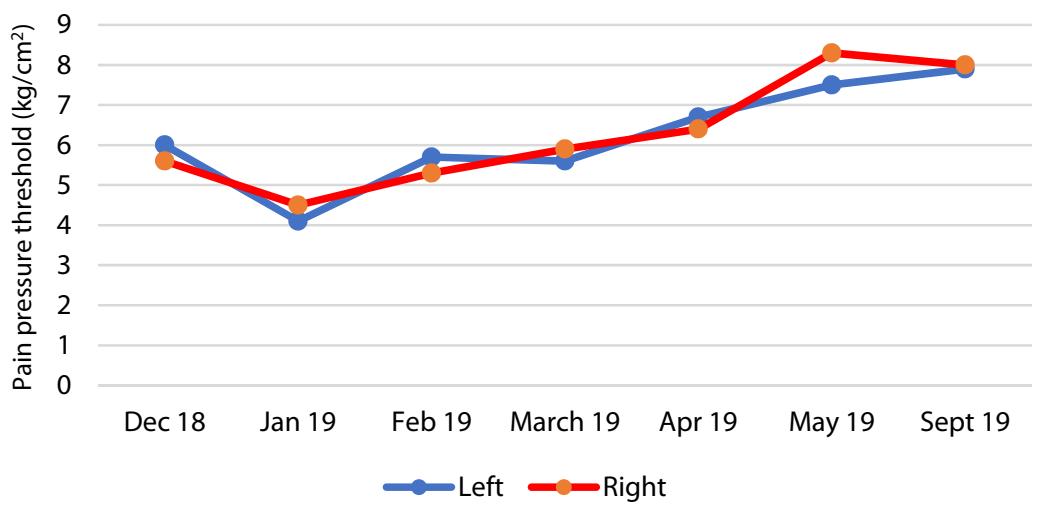

Figure 4. Pain pressure threshold of right and left side of body side. 
At initial and final measurements the distance between right costal margin and left ASIS was $27.5 \mathrm{~cm}$, while the distance between left costal margin and right ASIS was initially $26.5 \mathrm{~cm}$ and at the end of study $28 \mathrm{~cm}$, thus increasing by $1.5 \mathrm{~cm}$.

No structural lower-limb length discrepancies were detected, since the distance from upper margin of greater trochanter and lower margin of lateral malleolus was bilaterally $82 \mathrm{~cm}$. Initially the distance between the right and left ASIS and lower margin of lateral malleolus was $91 \mathrm{~cm}$ and $93 \mathrm{~cm}$, respectively, revealing the functional lower-limb length discrepancy of $2 \mathrm{~cm}$. But on final evaluation the functional limb length inequality was fully resolved.

\section{DISCUSSION}

We consider improvement of thoracic hyperkyphosis alongside with reduced forward head posture and thoracic dextroscoliosis as the main findings of this study. Correspondingly, the subject reported increased satisfaction with her posture. Additionally, reduced subjective stiffness in spinal extension, as well improvement of back pain after treatment was noticed.

In consistent with current study, the reduction of thoracic hyperkyphosis $[16,22,27,40]$ and forward head posture $[12,16,20,40]$ after multimodal PT program has been shown as well by other studies. Likewise, Yoo [40] observed upper thoracic pain reduction after performing of thoracic stretching and thoracic extension exercise, as well strengthening exercises for cervical and scapular muscles for one month in a 36-year-old male subject, who was treated for upper thoracic pain, forward head posture and rounded shoulders. Likewise, application of thoracic extension traction, thoracic extension exercises and manual thoracic mobilizations for 9 weeks resulted in reduced pain and disability among 10 adult patients alongside with improvement in thoracic hyperkyphosis [27]. After treating an adolescent girl for thoracic hyperkyphosis, forward head posture, neck and back pains, headaches, and various other health issues with simultaneous anterior thoracic translation and thoracic extension traction over a period of 13 months, $80-100 \%$ improvement in all of the initial health complaints alongside with remarkably improved posture was observed [25]. And, a 32-year-old male subject reported substantial improvement in middle and low-back pain, neck pain, as well the reduction of headaches and dizziness, forward head posture and thoracic hyperkyphosis after cervical and thoracic extension exercises, traction, and manipulation program that lasted for 13 weeks [16]. 
On the opposite, some studies on adult population do not support our findings about postural improvements to be accompanied by improvement in subjective symptoms such as in back pain [4] or quality of life [4, 18, 22]. Glassman et al. [18] investigated the effects of conservative treatment in patients with lumbar scoliosis and found no changes in quality of life among treatment group, and some improvement of health status among patients who received no treatment. Current study did not assess all aspects of quality of life, yet documented the changes in subjective satisfaction about the posture, where the subject expressed marked satisfaction with her neck and thoracic posture during and after intervention. Similarly, Katzman et al. [22] found that, exercise therapy for postural disorders resulted in improved self-image and satisfaction with body image, yet no differences between treatment and control group for quality of life were detected. Differences between our study and the study of Glassman et al. [18] might be attributed as well to the aspect that Glassman et al. [18] included both high and low symptom subjects into the analysis, and the severity of disorder could influence patients' responses to treatment, as well the subjects were treated for lumbar scoliosis, meanwhile the participant in the current study had mild scoliosis in thoracic region, and several other postural complaints, such as thoracic hyperkyphosis and forward head posture. Additionally, the specify of intervention protocols would certainly affect outcomes, and while the subjects in the study by Glassman et al. [18] were treated with medication, physical therapy, exercise, injections/blocks, chiropractic care, pain management, bracing, or bed rest, the emphasis in our study was set on individually adjusted and carefully selected muscle strengthening and spinal mobility exercises for affected body segments, with simultaneous incorporation of newly acquired postural habits into daily life activities. The profile of PT program applied in current study has many similarities with the program used by Katzman et al. [22], where elderly subjects with hyperkyphotic thoracic spine experienced significant improvement in hyperkyphosis and self-image, analogously to the results obtained in the present study.

On the contrary to Bautmans et al. [4], who could not detect the reduction in back pain of elderly patients with osteoporosis and thoracic hyperkyphosis in comparison with control group after application of exercises, taping and spinal manual mobilizations, subject in the present study reported that after PT program the thoracic spine extension mobility was noticeably freer and less painful, and these finding were substantiated by increase in the pain pressure threshold of right and left paraspinal muscles by $2.4 \mathrm{~kg} / \mathrm{cm}^{2}$ and $1.9 \mathrm{~kg} \mathrm{~kg} / \mathrm{cm}^{2}$, respectively. Otherwise, therapeutic program used by Bautmans et al. [4] improved posture, therefore the lack of 
impact on pain might be related to shorter duration of program compared to our study ( 3 months versus 9 months), as well differences in subjects' health status (osteoporotic versus not osteoporotic subjects), age, and the specific characteristics of treatment protocol itself. The PT protocol in current study might be considered more intensive, with treatment sessions lasting longer, more exercises were included and applied not only to thoracic region, but as well to neck, lower back and pelvis.

To summarize, multimodal PT protocol with active strengthening, mobility and posture correction exercises, manual manipulations on thoracic spine and back massage was effective in improving subjects' posture and attenuating back pain and stiffness.

\section{REFERENCES}

1. Abdel-Aziem AA, Draz AH. (2016) Efficacy of deep neck flexor exercise for neck pain: a randomized controlled study. Turk J Phys Med Rehab, 62: 107115. https://doi.org/10.5606/tftrd.2016.84565

2. Amabile AH, Bolte JH, Richter SD. (2017) Atrophy of gluteus maximus among women with a history of chronic low back pain. PLoS One, 12: e0177008. https://doi.org/10.1371/journal.pone.0177008

3. Arroyo-Morales M, Olea N, Martínez MM, Hidalgo-Lozano A, Ruiz-Rodríguez C, Díaz-Rodríguez L. (2008) Psychophysiological effects of massagemyofascial release after exercise: a randomized sham-control study. J Altern Complement Med, 14: 1223-1229. https://doi.org/10.1089/acm.2008.0253

4. Bautmans I, Van Arken, J, Van Mackelenberg M, Mets T. (2010) Rehabilitation using manual mobilization for thoracic kyphosis in elderly postmenopausal patients with osteoporosis. J Rehab Med, 42: 129-135.

https://doi.org/10.2340/16501977-0486

5. Bayattork M, Sköld MB, Sundstrup E, Andersen LL. (2020) Exercise interventions to improve postural malalignments in head, neck, and trunk among adolescents, adults, and older people: systematic review of randomized controlled trials. J Exerc Rehab, 16: 36-48. https://doi.org/10.12965/jer.2040034.017

6. Bennell KL, Metthews B, Greig A, Briggs A, Kelly A, Sherburn M, Larsen J, Wark, J. (2010) Effects of an exercise and manual therapy program on physical impairments, function and quality-of-life in people with osteoporotic vertebral fracture: a randomised, single-blind controlled pilot trial. BMC Musculoskeletal Disorder, 11:36. https://doi.org/10.1186/1471-2474-11-36

7. Berdishevsky H. (2016) Outcome of intensive outpatient rehabilitation and bracing in an adult patient with Scheuermann's disease evaluated by radiologic imaging - a case report. Scoliosis Spinal Disord, 11: 40.

https://doi.org/10.1186/s13013-016-0094-7 
8. Bettany-Saltikov J, Turnbull D, Ng SY, Webb R. (2017) Management of spinal deformities and evidence of treatment effectiveness. Open Orthop J, 11: 1521-1547. https://doi.org/10.2174/1874325001711011521

9. Brady RJ, Dean JB, Skinner TM, Gross MT. (2003) Limb length inequality: clinical implications for assessment and intervention. J Orthop Sports Phys Ther, 33: 221-234. https://doi.org/10.2519/jospt.2003.33.5.221

10. Cagnie B, Dickx N, Peeters I, Tuytens, J, Achten E, Cambier D, Danneels L. (2007) The use of functional MRI to evaluate cervical flexor activity during different cervical flexion exercises. J Appl Physiol, 104: 230-235. https://doi.org/10.1152/japplphysiol.00918.2007

11. Chiu TT, Ku WY, Lee MH, Sum WK, Wan MP, Wong CY, Yuen CK. (2002) A study on the prevalence of and risk factors for neck pain among university academic staff in Hong Kong. J Occup Rehabil, 12: 77-91. https://doi.org/10.1023/A:1015008513575

12. Cho J, Lee E, Seungwon Lee S. (2017) Upper thoracic spine mobilization and mobility exercise versus upper cervical spine mobilization and stabilization exercise in individuals with forward head posture: a randomized clinical trial. BMC Musculoskelet Disord, 18: 525.

https://doi.org/10.1186/s12891-017-1889-2

13. Ensrud KE, Black DM, Harris F, Ettinger B, Cummings SR. (1997) Correlates of kyphosis in older women. The fracture intervention trial research group. J Am Geriatr Soc, 45: 682-687. https://doi.org/10.1111/j.1532-5415.1997.tb01470.x

14. Ettinger B, Black DM, Palermo L, Nevitt MC, Melnikoff S, Cummings, S-R. (1994) Kyphosis in older women and its relation to back pain, disability and osteopenia: the study of osteoporotic fractures. Osteoporos Int, 4: 55-60. https://doi.org/10.1007/BF02352262

15. Fon GT, Pitt MJ, Thies AC Jr. (1980) Thoracic kyphosis: range in normal subjects. AJR Am J Roentgenol 134: 979-983. https://doi.org/10.2214/ajr.134.5.979

16. Fortner MO, Oakley PA, Harrison DE. (2018) Alleviation of chronic spine pain and headaches by reducing forward head posture and thoracic hyperkyphosis: a $\mathrm{CBP}^{\circledast}$ case report. J Phys Ther Sci, 30: 1117-1123.

https://doi.org/10.1589/jpts.30.1117

17. Ghamkhar L, Kahlaee AH. (2019) Is forward head posture relevant to cervical muscles performance and neck pain? A case-control study. Braz J Phys Ther, 23: 346-354. https://doi.org/10.1016/j.bjpt.2018.08.007

18. Glassman SD, Carreon LY, Shaffrey CI, Polly DW, Ondra SL, Berven SH, Bridwell KH. (2010) The costs and benefits of nonoperative management for adult scoliosis. Spine (Phila Pa 1976), 35: 578-582. https://doi.org/10.1097/BRS.0b013e3181b0f2f8

19. Haefeli M, Elfering A, Kilian R, Min K, Boos N. (2006) Nonoperative treatment for adolescent idiopathic scoliosis: a 10- to 60-year follow-up with special reference to health-related quality of life. Spine (Phila Pa 1976), 31: 355-367.

https://doi.org/10.1097/01.brs.0000197664.02098.09 
20. Harman K, Hubley-Kozey CL, Butler H. (2005) Effectiveness of an exercise program to improve forward head posture in normal adults: a randomized, controlled 10-week trial. J Man Manip Ther, 13: 163-176.

https://doi.org/10.1179/106698105790824888

21. Janicki JA, Alman B. (2007) Scoliosis: review of diagnosis and treatment. Paediatr Child Health, 12: 771-776. https://doi.org/10.1093/pch/12.9.771

22. Katzman WB, Vittinghoff E, Lin F, Schafer A, Long RK, Wong S, Gladin A, Fan B, Allaire B, Kado DM, Lane NE. (2017) Targeted spine strengthening exercise and posture training program to reduce hyperkyphosis in older adults: results from the study of hyperkyphosis, exercise, and function (SHEAF) randomized controlled trial. Osteoporos Int, 28: 2831-2841.

https://doi.org/10.1007/s00198-017-4109-x

23. Kim JY, Kwag KI. (2016) Clinical effects of deep cervical flexor muscle activation in patients with chronic neck pain. J Phys Ther Sci, 28: 269-273. https://doi.org/10.1589/jpts.28.269

24. Magee DJ. (2014) Orthopedic Physical Assessment. Canada: Elsevier Inc, 720.

25. Miller JE, Oakley A, Levin SB, Harrison DE. (2017) Reversing thoracic hyperkyphosis: a case report featuring mirror image thoracic extension rehabilitation. J Phys Ther Sci, 29: 1264-1267. https://doi.org/10.1589/jpts.29.1264

26. Morrissy RT, Weinstein SL. (2006) Lovell and Winter's Pediatric Orthopaedics. Philadelphia: Lippincott Williams \& Wilkins, 693-762.

27. Oakley PA, Jaeger JO, Brown JE, Polatis TA, Clarke JG, Whittler CD, Harrison DE. (2018) The $\mathrm{CBP}^{\circledast}$ mirror image ${ }^{\circledast}$ approach to reducing thoracic hyperkyphosis: a retrospective case series of 10 patients. J Phys Ther Sci, 30: 1039-1045. https://doi.org/10.1589/jpts.30.1039

28. Richards J. (2018) The Comprehensive Textbook of Clinical Biomechanics. China: Elsevier Ltd, 283.

29. Payne WK, Ogilvie JW, Resnick MD, Kane RL, Transfeldt EE, Blum RW. (1997) Does scoliosis have a psychological impact and does gender make a difference? Spine (Phila Pa 1976), 22: 1380-1384.

https://doi.org/10.1097/00007632-199706150-00017

30. Romano M, Negrini A, Parzini S, Tavernaro M, Zaina F, Donzelli S, Negrini S. (2015) SEAS (scientific exercises approach to scoliosis): a modern and effective evidence-based approach to physiotherapic specific scoliosis exercises. Scoliosis, 10: 3. https://doi.org/10.1186/s13013-014-0027-2

31. Rrecaj-Malaj S, Beqaj S, Krasniqi V, Qorolli M, Tufekcievski A. (2020) Outcome of 24 weeks of combined Schroth and Pilates exercises on Cobb angle, angle of trunk rotation, chest expansion, flexibility and quality of life in adolescents with idiopathic scoliosis. Med Sci Monit Basic Res, 26: e920449.

https://doi.org/10.12659/MSMBR.920449

32. Ryan PJ, Blake G, Herd R, Fogelman I. (1994) A clinical profile of back pain and disability in patients with spinal osteoporosis. Bone, 15: 27-30.

https://doi.org/10.1016/8756-3282(94)90887-7 
33. Shaheen A, Basuodan R. (2012) Quantitive assessment of head posture of young adults based on lateral view photographs. J Phys Ther, 24: 391-394. https://doi.org/10.1589/jpts.24.391

34. Singla D, Veqar Z. (2017) Association between forward head, rounded shoulders, and increased thoracic kyphosis: a review of the literature. J Chiropr Med, 16: 220-229. https://doi.org/10.1016/j.jcm.2017.03.004

35. Spencer L, McKenna L, Fary R, Jacques A, Briffa K. (2019) Upper back pain in postmenopausal women and associated physical characteristics. PLoS ONE, 4: e0220452. https://doi.org/10.1371/journal.pone.0220452

36. Terry MA, Winell JJ, Green DW, Schneider R, Peterson M, Marx RG, Widmann RF. (2005) Measurement variance in limb length discrepancy: clinical and radiographic assessment of interobserver and intraobserver variability. J Pediatr Orthop, 25: 197-201. https://doi.org/10.1097/01.bpo.0000148496.97556.9f

37. Trobisch P, Suess O, Schwab F. (2010) Idiopathic scoliosis. Dtsch Arztebl Int, 107: 875-884. https://doi.org/10.3238/arztebl.2010.0875

38. Vanti C, Ferrari S, Morsillo F, Tosarelli D, Pillastrini P. (2008) Manual therapy for non-specific thoracic pain in adults: review of the literature. J Back Musculoskelet, 21: 143-152. https://doi.org/10.3233/BMR-2008-21301

39. Weiss HR, Weiss G, Petermann, F. (2003) Incidence of curvature progression in idiopathic scoliosis patients treated with scoliosis in-patient rehabilitation (SIR): an age- and sex-matched controlled study. Pediatr Rehabil, 6: 23-30. https://doi.org/10.1080/1363849031000095288

40. Yoo W-G. (2013) Effect of thoracic stretching, thoracic extension exercise and exercises for cervical and scapular posture on thoracic kyphosis angle and upper thoracic pain. J Phys Ther Sci, 25: 1509-1510.

https://doi.org/10.1589/jpts.25.1509

\section{Correspondence to:}

Kirkke Reisberg

Tartu Health Care College

Nooruse 5, Tartu

50411, Estonia

E-mail: kirkkereisberg@nooruse.ee 